\title{
Menjembatani Aksesibilitas Pelayanan KesehatanMasyarakat Miskin di Kawasan Ruli Kota Melalui Institusi Lokal
}

\author{
Johannes Tarigan ${ }^{1}$, Yusak Hentrias Ferry ${ }^{2}$, Fredy Simanjuntak ${ }^{3}$, \\ Zakaria Lumban Gaol $^{4}$, Ester Novia Padidi ${ }^{5}$, Dian Kristina Sijabat ${ }^{6}$ \\ 1, 2,3 Prodi Teologi, STT Real Batam \\ $4,5,6$ Prodi PAK, STT Real Batam \\ *jhnnstarigan@gmail.com
}

\begin{abstract}
As we know that humans have physical, mental and spiritual needs. All parts of this human need to be fulfilled. In an effort, LPPM Real Batam together with NGO Partners Cares for the Nation started a pilot project to provide health, food and clothing assistance to the poor in the city of Batam. The purpose of the activity is to provide counseling as well as education and assistance in the form of free food and medication. The implementation method for this community service program is counseling families and health checks from children to the elderly. From the results of the evaluation with the PKM team, this activity is very useful because in addition to easing the burden on the poor, it also helps people who have problems with their health.
\end{abstract}

Keywords: Health Services, The Poor, Batam City

\section{Abstrak}

Sebagaimana yang kita ketahui bahwa manusia mempunyai kebutuhan jasmani, jiwani dan rohani. Semua bagian dari manusia ini perlu dipenuhi. Dalam Upaya LPPM Real Batam bersama Mitra LSM Peduli bangsa memulai pilot-project untuk mberikan bantuan kesehatan, makanan dan pakaian kepada masyarakat miskin di kota Batam. Tujuan kegiatan adalah untuk memberikan penyuluhan serta edukasi dan bantuan berupa makanan dan pengobatan gratis. Metode pelaksanaan pada program pengabdian masyarakat ini, yaitu penyuluhan keluarga-keluarga dan pemeriksaan kesehatan dari mulai anak-anak sampai lansia. Dari hasil evaluasi dengan team PKM, kegiatan ini sangat bermanfaat karena selain meringankan beban warga miskin , juga membantu mengatasi warga yang bermasalah dengan kesehatannya.

Kata kunci: Pelayanan Kesehatan, Warga Miskin, Kota Batam

\section{PENDAHULUAN}

Menolong kaum marginal bukanlah seberapa banyak yang untuk diusahakan dan juga bukan sebuah kontes untuk menghitung berapa banyak orang yang dapat untuk ditolong. Hal ini adalah tentang kerelaan untuk memberikan apa yang dimiliki untuk membantu kaum marginal, sekalipun bantuan yang diberikan terbilang sangat sedikit atau kecil. Paul Shane Spear berkata, "As one person I cannot change the world, but I can change the world of one person."

Alasan ekonomi kerap membuat masyarakat miskin dan marginal mengurungkan niatnya untuk berobat. Begitu juga ketika ikut program jaminan kesehatan, mereka tak memiliki cukup uang untuk membayar iuran. Fakta tersebut mendorong LPPM Real Batam Bersama mitra PkM LSM Peduli Bangsa menciptakan inovasi untuk membantu warga tidak mampu. Program ini dibuat untuk memastikan setiap warga miskin bisa mendapatkan layanan kesehatan secara cuma-cuma.

Masalah aksesibilitas penduduk miskin terhadap pelayanan kesehatan menjadipersoalan serius yang belum terselesaikan. Aksesibilitas yang dimaksud mencakup akses fasilitas kesehatan, akses biaya kesehatan dan akses informasi terkait kesehatan.2 Selain itu, menurut Prasetyo, ada biaya akses lainnya yang harus dipenuhi yaitu transportasi, penginapan dan makanan termasuk opportunity cost (biaya yang timbul akibat tidak bekerja untuk memperoleh jasa kesehatan). ${ }^{1}$

\section{Permasalahan Lapangan}

Kegiatan ini dimaksudkan untuk menyasar lokasi-lokasi rumah liar dimana banyak orang menghadapi masalah kesehatan tapi tidak mampu berobat karena faktor ekonomi. Maka PKM ini bertujuan membantu warga di 4 lokasi Kawasan rumah liar seperti Kampung Baru, Baloi Kolam,

\footnotetext{
${ }^{1}$ Eko Prasetyo, Orang Miskin Dilarang Sakit (Yogyakarta: Resist Book, 2007).
} 
Baloi ATB, Kawasan Industri Sekupang. Masalah penting lainnya adalah akses penduduk miskin terhadap pelayanan kesehatan, penanganan masalah gizi buruk, penanggulangan wabah penyakit menular, pelayanan kesehatan di daerah bencana dan kurangnya pemenuhan jumlah dan penyebaran tenaga kesehatan. Rasio tenaga kesehatan terhadap jumlah penduduk yang harus dilayani masih rendah. Fasilitas kesehatan belum tersebar merata dan hanya menjangkau masyarakat di pusat-pusat kota. $^{2}$ Paradigma pembangunan yang topdown dan sentralistis kentara mempengaruhi kebijakankebijakan kesehatan pemerintah yang blueprintoriented. Sistem pelayanan kesehatan dituntut mengikuti petunjuk teknis pemerintah tanpa mempertimbangkan kondisi masyarakat yang variatif. Padahal, pendekatan pembangunan yang sentralistis dan bersifat seragam sulit menyentuh berbagai kebutuhan lokal yang sangat bervariasi. ${ }^{3}$

Institusi lokal, sebagai bagian potensi masyarakat dalam tulisan ini dipandang mampu mengupayakan pelayan an kesehatan yang merata. Tentu saja hal tersebut terwujud bila dioptimalkan dan mendapat dukungan dari berbagai pihak. Institusi lokal mempunyai kelebihan-kelebihan yang tidak dimiliki institusi bentukan pemerintah. Institusi lokal merupakan endapan dari nilai-nilai dan aktivitas lokal yang telah terinstitusionalisasi dan dapat diarahkan untuk mengupayakan kepentingan bersama termasuk juga pelayanan kesehatan. ${ }^{4}$

Kesehatan dalam bingkai teori fungsional struktural dipandang sebagai item yang berfungsi bagi terselenggaranya kehidupan masyarakat yang tertib, seimbang dan teratur. Pandangan demikian berangkat dari asumsi bahwa kesehatan individu akan turut mempengaruhi tatanan sosial yang berlaku karena berjalannya sistem sosial. Sebaliknya, perspektif teori konflik memandang kesehatan sebagai bentuk kekuatan (power) dari individu. Asumsi dasarnya adalah siapa yang paling berkuasa akan diuntungkan dari kualitas kesehatan individu. Pada titik ekstrem dari teori ini, kesehatan menjadi representasi dari akumulasi penghasilan. Kondisi tersebut mengamini pendapat Kaplan dkk. 1996, dan Lynch dkk, 1998 bahwa ketidaksetaraan penghasilan berhubungan dengan tingkat pengeluaran untuk kesehatan. Pada akhirnya, minimnya alokasi biaya untuk kesehatan mempengaruhi tingkat kesehatan individu. ${ }^{5}$ Asumsi yang demikian akan menempatkan individu sebagai faktor mutlak penentu rendahtingginya kualitas kesehatan dan mengabaikan kemungkinan adanya faktor-faktor lain. Navarro membantah jika individu dijadikan penyebabutamamunculnya masalah kesehatan individual. ${ }^{6}$

Pada kenyataannya, kelas sosial sangat berpengaruh pada kehidupan sosial individu tidak hanya berkaitan dengan relasi dan interaksi sosial, melainkan dengan kebutuhan hidupnya. Menurut Higgs dan Scambler salah satu unsur yang penting dari kelas sosial adalah efeknya terhadap kehidupan masyarakat. ${ }^{7}$ Namun, Kesenjangan spasial bukanlah faktor utama penghambat aksesibilitas masyarakat miskin pada pelayanan kesehatan. Akses masyarakat miskin terhadap pelayanan kesehatan masih sering terkendala oleh faktor internal dan eksternal masyarakat. ${ }^{8}$

Sistem pelayanan kesehatan sejauh ini sangat didominasi peran pemerintah sebagai aktor yang memiliki legitimasi untuk mengatur pembangunan kesehatan. Pemerintah pula yang mempunyai kendali untuk menyediakan pelayanan sosial bagi segala kebutuhan masyarakat. Padahal pelayanan sosial seharusnyadiartikan sebagai tindakan memproduksi, mengalokasi dan mendistribusi

\footnotetext{
${ }^{2}$ Puji Restiyani, Fitriyah, and Lusia Astrika, “Aksesibilitas Masyarakat Miskin Dalam Memperoleh Pelayanan Kesehatan (Studi Kasus Di Kawasan Kampung Tambak Mulyo Kelurahan Tanjung Mas Semarang," Journal of Politic and Government Studies 2, no. 3 (2013): 1-13.

${ }^{3}$ Soetomo, "Persoalan Pengembangan Institusi Masyarakat," Jurnal Ilmu Sosial dan Politik. 10, no. 1 (2006): 51-69.

${ }^{4}$ Norman Uphoff, Local Institutional Development: An Analytical Sourcebook (Connecticut: Kumarian Press, 1986).80-109

${ }^{5}$ Kevin White, Pengantar Sosiologi Kesehatan Dan Penyakit, 3rd ed. (Jakarta: Rajawali Press, 2011). 102

${ }^{6}$ William C Cockerham, Medical Sociology, 5th ed. (New Jersey: Prentice-Hall: Englewood Cliffs, 1992). 260

${ }^{7}$ Graham Scambler and Paul Higgs, Explaining Health Inequalities :How Useful Are Concepts of Social Class? In Modernity, Medicine and Health (London: Routledge, 1998).6

${ }^{8}$ Ferdinandus, "Akses Masyarakat Miskin Terhadap Pelayanan Kesehatn Di Kabupaten Bolaang Mongondow” (Universitas Gadjah Mada, 2008).33
} 
sumberdaya sosial kepada public. ${ }^{9}$

\section{Sumber Dana}

Usulan dana pengabdian diajukan pada SekolahTinggi Teologi REAL Batam dengan Mitra LSM Peduli bangsa, sumbangan siswa, bantuan gereja, sumbangan pribadi. Diharapkan melalui program pelayanan Kesehatan ini dapat meringankan beban penderitaan masyarakat sekaligus menjangkau yang belum "percaya" dengan kasih Kristus. Pelayanan ini juga mendukung program pemerintah dalam masa tanggap darurat dan masa pemulihan. Pelayanan yang di berikan dapat menyentuh dan membangun nilai-nilai kehidupan, sehingga dapat memperlengkapi warga secara jasmani dan rohani. Kegiatan ini dilaksanakan pada tanggal 16 Nopember 2019 di Batam.

\section{Tujuan Kegiatan}

a. Memberi informasi kepada penduduk mengenai kesehatan dan cara menyikapi perubahanperubahan yang terjadi pada usia tersebut melalui penyuluhan. Pemeriksaan rutin seperti berat badan dan tekanan darah juga dilakukan untuk memantau kesehatan lansia sedini mungkin, Dalam halini LPPM Real Batam bekerjasama dengan LSM Peduli Bangsa juga mengadakan kegiatan pengobatan gratis dengan mendatangkan dokter serta ahli medis.

b. Memberikan semangat dan motivasi bagi warga jemaat yang kemalangan

c. Membantu secara finansial,makanan serta pakaian

\section{Manfaat Kegiatan}

Kegiatan PKM STT Real Batam Bersama mitra PkM LSM Peduli Bangsa ini memberikan layanan kesehatan berkala bagi warga lanjut usia. Ini meliputi pemeriksaan kadar gula darah, kolesterol, asam urat, maupun tekanan darah. Pemeriksaan dilakukan di tingkat desa dengan menghadirkan petugas medis. Langkah-langkah itu diharapkan menjadi upaya preventif guna mengetahui potensi gangguan kesehatan warga lanjut usia. Warga masyarakat dampingan tersebut tersebut mendapat pelayanan kesehatan dan obat tanpa khawatir untuk membayar biaya nya.

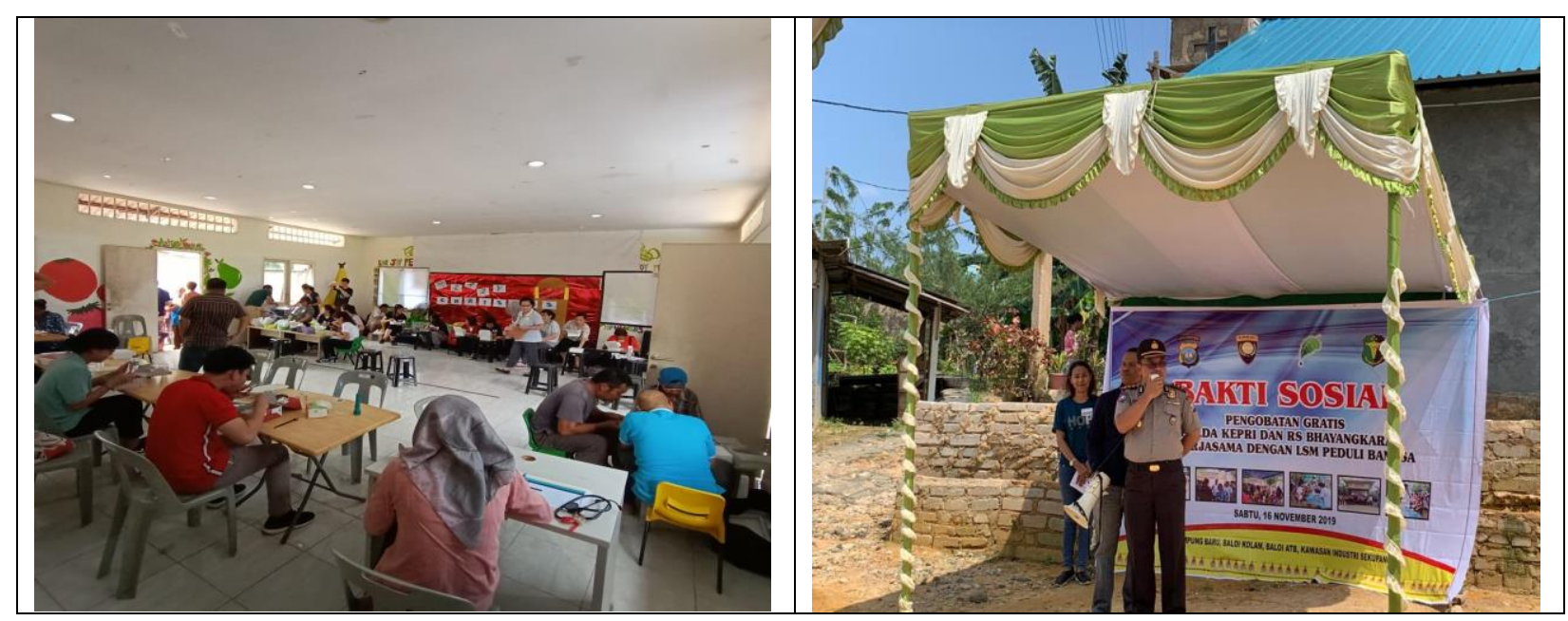

Gambar 1. Pemasangan Posko Pelayanan Kesehatan Masyrakat

\section{Tahapan Kegiatan}

Tahap-tahap yang dilaksanakan dalam kegiatan ini:

a. Tahap Sosialisasi, tahap ini dimulai dengan mengenal karakter dari kelompok sasaran sehingga akan memudahkan dalam melaksanakan program yang direncanakan agar individuindividu dalam kelompok pada program ini mampu bangkit dan percaya diri pulih.

b. Tahap Pendampingan pada tahap ini, kelompok didampingi untuk dapat menjalankan kegiatan dengan pastoral care di sertai dengan pengertian

\footnotetext{
9 Janianton Damanik, "Menuju Pelayanan Sosial Yang Berkeadilan," Jurnal Ilmu Sosial dan Ilmu
} Politik 15, no. 1 (2011): 1-14. 
c. Tahap pemantauan pasca kegiatan, yang bertujuan untuk melihat pertumbuhan pemulihan para pengungsi dan korban

\section{Metode Penelitian}

Berdasarkan masalah yang dikemukakan tersebut di atas, maka Tim pengabdian kepada masyarakat (abdimas) melakukan penelitian singkat. Penelitian ini bersifat deskriptif kualitatif, dilaksanakan di Kawasan ruli di 4 titik di kota Batam. Pengumpulan data dilakukan dengan wawancara lisan dampak sosial psikologis warga miskin. Observasi tentang kondisi dan analisa dokumen dan pemetaan yang terkait dengan kondisi wilayah dan jumlah masyrakat miskin. Selanjutnya data yang terkumpul dianalisis secara deskriptif kualitatif. Langkah Analisa sebagai berikut:

1. Pada tahap pertama untuk pemecahan masalah terbatasnya rasa minder dan kekuatiran akan kondisi kesehatan. Untuk meningkatkan pengetahuan maupun percaya diri mereka, serta untuk meningkatkan pemberdayaan diri sehingga ada kegairahan dalam bentuk pemberdayaan maka Tim merencanakan pendekatan berupa penyuluhan, Konsultasi dan mendoakan.

2. Tahap ketiga, untuk membangun sikap untuk meningkatkan percaya diri, bagi mereka yang kehilangan pekerjaan dilakukan dengan diskusi, tanya jawab dan mencari solusi berbagai kendala saat itu yang sering mereka alami berkaitan dengan kondisi di Kawasan ruli.

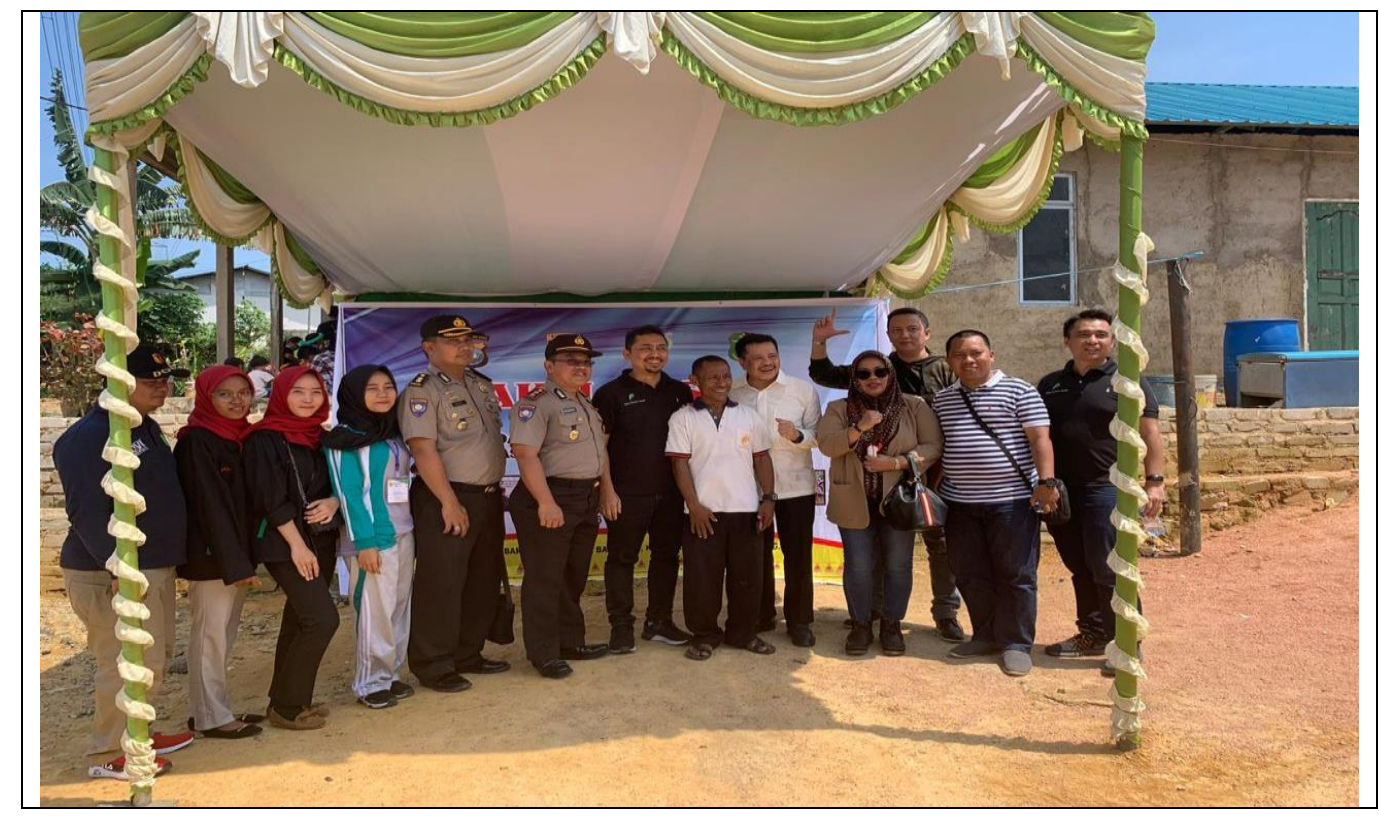

Gambar 2. Foto Bersama Tim Relawan, dokter, perawat dan Pihak keamanan

\section{Metode Pelaksanaan}

Metode pelaksanaan pada program pengabdian masyarakat ini,

\begin{tabular}{|c|c|c|c|c|c|c|}
\hline \multirow{2}{*}{ No } & \multirow{2}{*}{ Uraian Kegiatan } & \multicolumn{5}{|c|}{ Waktu 2019} \\
\hline & & Okt & Nov & Des & Jan & Feb \\
\hline 1 & Pendataan Keluhan sakit warga & & & & & \\
\hline 2 & Pengecekan Kesehatan & & & & & \\
\hline 3 & $\begin{array}{l}\text { Pelayanan Tim Medis \& } \\
\text { Konsultasi kesehatan }\end{array}$ & & & & & \\
\hline 4 & Pemberian Makan Bergizi & & & & & \\
\hline 5 & Penarikan seluruh team & & & & & \\
\hline
\end{tabular}

Berdasarkan pengamatan dan wawancara observasi lapangan yang telah diuraikan diatas, bahwa terdapat permasalahan sebagai berikut: 
Beberapa permasalahan yang dihadapi korban bencana yaitu:

1. Permasalahan lingkungan hidup

2. Populasi dan lingkungan yang padat

3. Pemukiman kumuh

4. Kekurangan gizi

5. Pembuangan sampah yang tidak pad tempatnya

6. Timbulnya penyakit-penyakit (batuk, flu, penyakit kulit dan gatal-gatal) ataupun penyakit menular diare karena kurangnya kebersihan di lingkungan dan tempat penampungan.
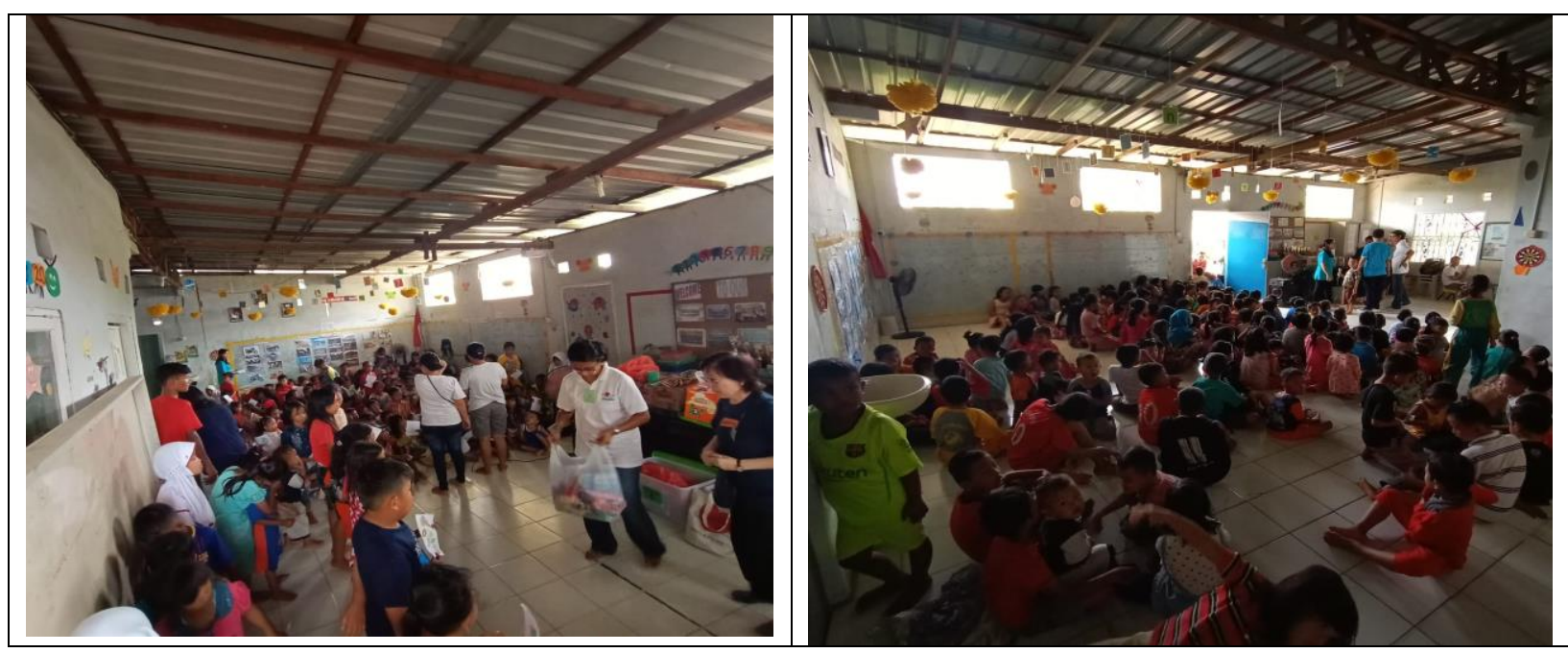

Gambar 3. Team Relawan Membagikan Makanan Bergizi kepada Anak-Anak

\section{Hasil Pembahasan}

Dari kegiatan pengabdian masyarakat melalui PKM. Dari 36 orang anggota team yang terdiri dari dosen, medical dokter yang di bagi empat group, secara maksimal mengerjakan hal hal di lapangan di dapati sebagai berikut:

Pelayanan Kesehatan di empat Kawasan ruli di kota Batam yang diiringi dengan pemberian makanan bergizi oleh tim PKM STT Real Batam yang melibatkan relawan dan Yayasan terhadap warga miskin mulai dari anak-anak sampai lansia. Tujuan aksi sosial untuk memberikan pelayanan Kesehatan, konsultasi Kesehatan, penyuluhan kesehatan, serta edukasi program Kesehatan keluarga kepada masyarakat yang termarginalkan dan miskin di Kawasan perumahan ruli di kota Batam. 


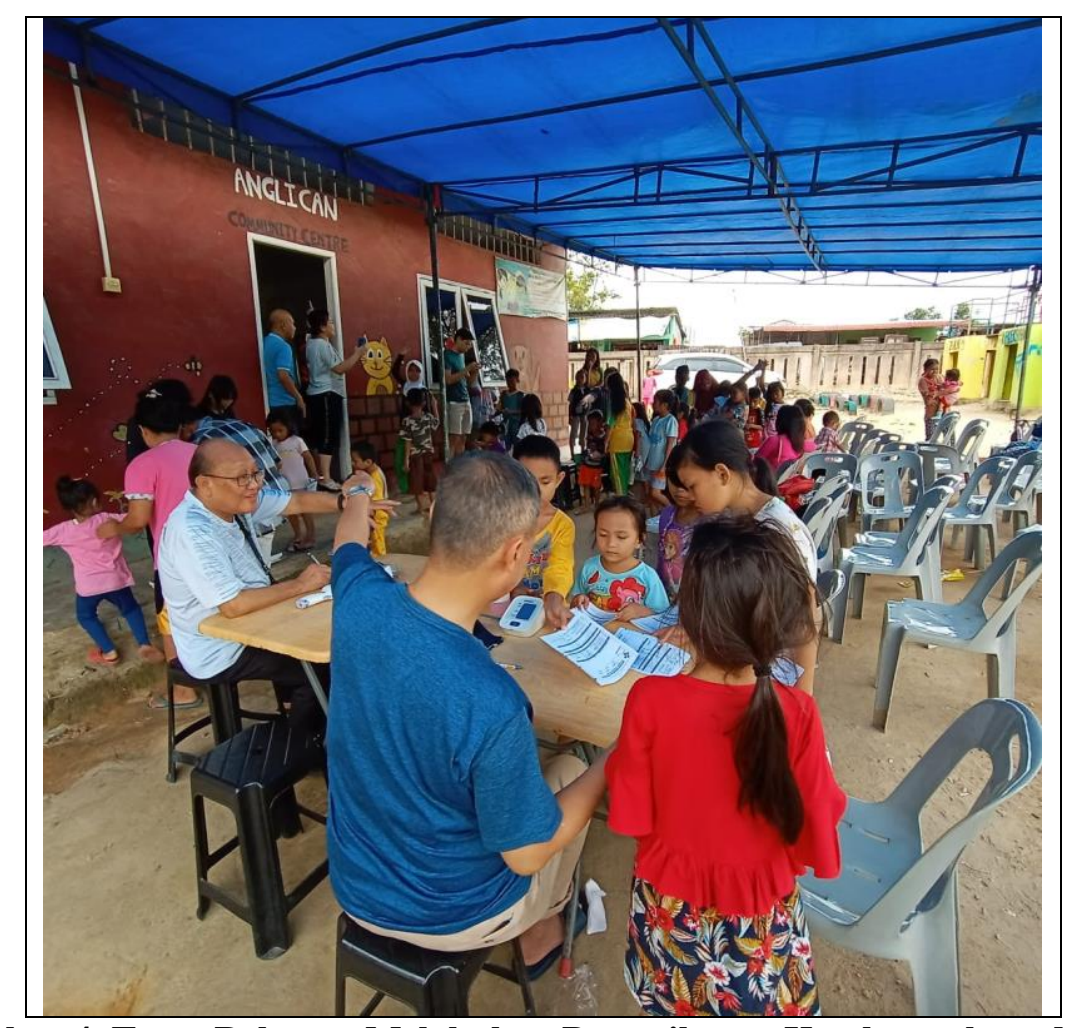

\section{Gambar 4. Team Relawan Melakukan Pemeriksaan Kesehatan kepada masyarakat}

Kebutuhan pangan, pakaian, shelter, fasilitas kesehatan. Berbagai kegiatan penyuluhan dan pemeriksaan kesehatan juga dilakukan yang melibatkan khalayak umum,

Aksi Pelayanan melibatkan tiga hal pokok, yaitu:

a. Edukasi dan pembangkitan kesadaran akan Kesehatan dan kebersihan lingkungan

b. Pelibatan Kebijakan dan Perencanaan Pemerintah

Dalam Widjaja, ${ }^{10}$ untuk dapat mempengaruhi kebijakan pemerintah dalam hal ini, masyarakat dapat menilai dan merasakan suatu kehidupan yang lebih baik; misalnya: tersedianya lapangan pekerjaan, perbaikan gizi, dan berkurangnya tingkat kemiskinan. Pengambil keputusan mempunyai kompetensi dalam sektor keamanan, sistem ekonomi, penyediaan akses lembaga keuangan, fasilitas informasi, kesehatan, kesejahteraan sosial, layanan administrasi kependudukan, dan penyediaan sarana sekolah formal. Kebijakan dan perencanaan pemerintah berperan untuk mencegah persoalan yang berlanjut, seperti sakit berkepanjangan, kekurangan gizi, frustrasi, perilaku negatif, pemiskinan, stunting, dan ketertinggalan sebagai dampak dari lingkungan Kawasan rumah liar dan kumuh tanpa intervensi dari pihak pengambil kebijakan pemerintah. Hal ini dimaksudkan untuk mencegah peluang terjadinya masyarakat yang dimarginalkan, sosial cost atau generation lost.

c. Aksi Pelayanan Kesehatan LPPM Bersama Mitra PkM

Dalam masyarakat golongan miskin, aksi ini dijalankan dengan menjunjung tinggi prinsip partisipasi, dimulai dari penyusunan rencana, identifikasi masalah, penetapan skala prioritas, tujuan, implementasi dan pemantauan, serta evaluasi akhir dalam proses pelayanan kesehatan. Program pelayanan Kesehatan bagi warga miskin ini tentu tidak akan dapat tercapai secara maksimal apabila hanya dilaksanakan dalam satu kali program, akan lebih baik apabila dilaksanakan secara berkala. Pelayanan Kesehatan warga miskin tidak cukup dilakukan pemerintah saja, tetapi harus melibatkan pihak lain seperti swasta, lembaga lembaga social serta masyarakat lingkungan di mana warga miskin berada, baik secara perorangan maupun terorganisir yang bekerja sama atas nama kemanusiaan. Unsur pelayanan sosial pokok yang harus dilakukan bersama seperti pemenuhan kebutuhan makan, kesehatan, pakaian, sedangkan unsur penunjang meliputi

${ }^{10}$ Fransiskus Irwan Widjaja, "Peran Gereja Terhadap Kehidupan Politik Di Wilayah Kepulauan Riau," Real Didache 1, no. 2 (2016): 117-140. 
publikasi, simpati masyarakat lingkungan dan konsultasi dan memotivasi warga miskin untuk hidup penuh semangat dan bijaksana.

Langkah yang dilakukan dalam upaya Pelayanan Kesehatan warga miskin antara lain:

a. Penyuluhan Kesehatan

b. Pendekatan proaktif artinya tidak menunggu adanya masalah, tetapi mencari masalah. Petugas kesehatan dan Tim relawan tidak hanya menunggu pasien datang ke kantor atau di tempat praktik mereka, tetapi harus turun ke masyarakat untuk mencari dan mengidentifikasi masalah yang ada di masyarakat, dan selanjutnya melakukan tindakan jika diperlukan

c. Pasien dilihat sebagai makhluk yang utuh sehingga terjadinya penyakit tidak semata-mata karena terganggunya sistem biologi, individual, tetapi dalam konteks yang luas, aspek biologis, psikologois, dan sosial. Dengan demikian pendekatannya harus secara menyeluruh atau holistik Membangun partisipasi.

d. Mediasi dan fasilitasi Kesehatan dibarengi dengan penyuluhan kepada masyarakat mengenai edukasi pola hidup sehat

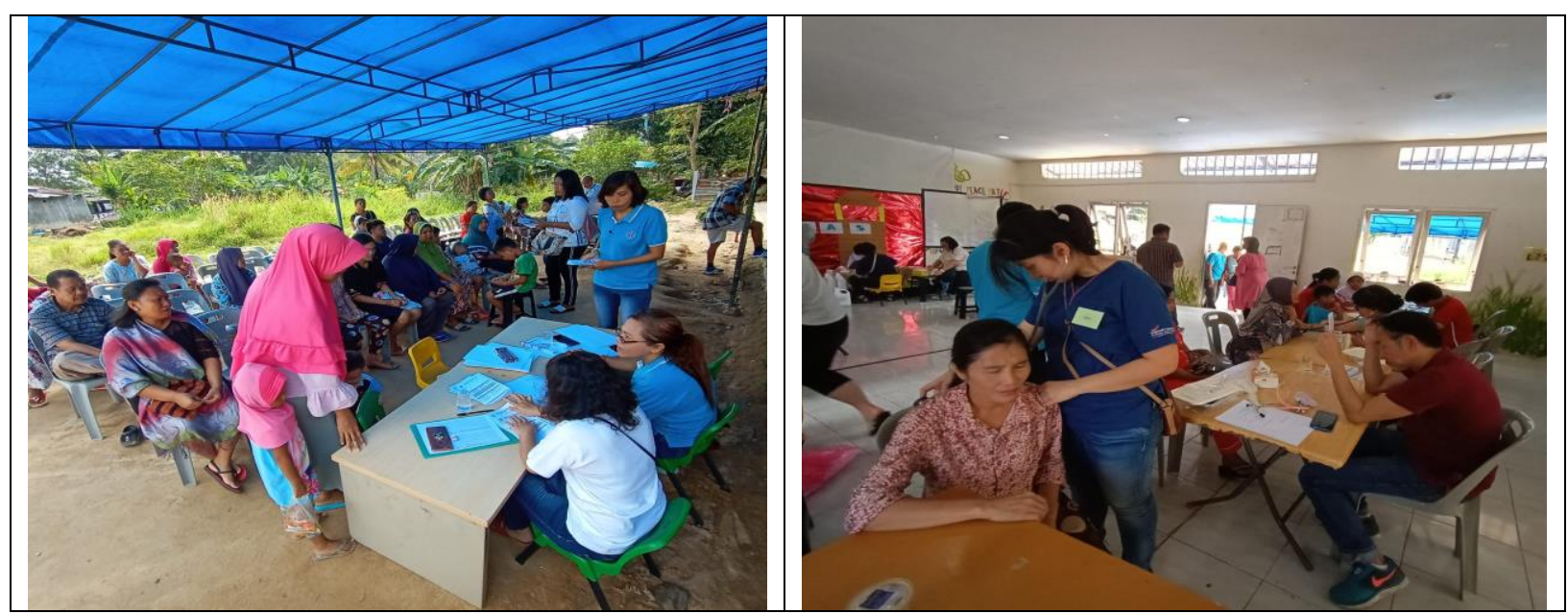

Gambar 5. Team Medis \&Relawan PKM Melakukan Pemeriksaan \& Konsultasi Kesehatan

\section{KESIMPULAN}

Kegiatan pengabdian masyarakat PKM Pelayanan kesehatan, khususnya warga miskin memerlukan berbagai kebutuhan kesejahteraan baik secara fisik maupun psikis agar semangat hidup Kembali bangkit. Untuk itu, hal-hal di bawah ini perlu di perhatikan:

1. Penanganan Masalah Psikologis.

Permasalahan nyata yang dialami warga yang tinggal di Kawasan ruli adalah, melemahnya semangat kemasyarakatan karena lingkungan yang kurang mendukung untuk hidup sehat dan sejahtera.

2. Pemenuhan kebutuhan fisik

Kebutuhan fisik merupakan masalahpokok bagipara warga miskin yang berada di kawasan ruli makanan, minuman dan lingkungan tempat tinggal yang ideal. Pentingnya pemenuhan kebutuhan fisik ini dikarenakan masalah ekonomi dan berbagai dampak kemiskinan yang dapat terjadi akibat PHK, kehilangan pekrjaan, sedikitnya lapangan pekerjaan.

3. Pemenuhan kebutuhan psikis

Perasaan yang dialami oleh warga yang tinggal di Kawasan ruli kebanyakan merasa rendah diri dan menganggap diri sebagai masyarakat kelas dua atau marginal.

4. Pemenuhan kebutuhan social

Warga yang tinggal di Kawasan ruli tentunya memiliki pemikiran yang sedikit peseimis akan nasib dan keadaan mereka jika sewaktu-waktu dilakukan penggusuran baik oleh pihak pemerintah maupun swasta.

\section{SARAN}


Saran yang di usulkan:

1. Dalam memberikan bantuan klesehatan kepada warga miskin yang tinggal di Kawasan ruli, perlu melakukan analisa kebutuhan agar tepat sasaran yaitu sesuai dengan kebutuhan, baik jenis maupun jumlahnya

2. Perlu kerja efisien dan efektif, supaya kerja bisa akurat dan tepat sasaran. Agar overlapping job bisa di minimalisir

3. Melakukan pemberdayaan agar masyarakat pelayanan kesehatan memerlukan keterlibatan sebanyak-banyaknya elemen masyarakat selain dari pemerintah dan swasta bahkan perguruan tinggi.

\section{DAFTAR PUSTAKA}

Cockerham, William C. Medical Sociology. 5th ed. New Jersey: Prentice-Hall: Englewood Cliffs, 1992.

Damanik, Janianton. "Menuju Pelayanan Sosial Yang Berkeadilan.” Jurnal Ilmu Sosial dan Ilmu Politik 15, no. 1 (2011): 1-14.

Ferdinandus. "Akses Masyarakat Miskin Terhadap Pelayanan Kesehatn Di Kabupaten Bolaang Mongondow.” Universitas Gadjah Mada, 2008.

Prasetyo, Eko. Orang Miskin Dilarang Sakit. Yogyakarta: Resist Book, 2007.

Restiyani, Puji, Fitriyah, and Lusia Astrika. "Aksesibilitas Masyarakat Miskin Dalam Memperoleh Pelayanan Kesehatan (Studi Kasus Di Kawasan Kampung Tambak Mulyo Kelurahan Tanjung Mas Semarang." Journal of Politic and Government Studies 2, no. 3 (2013): 1-13.

Scambler, Graham, and Paul Higgs. Explaining Health Inequalities :How Useful Are Concepts of Social Class? In Modernity, Medicine and Health. London: Routledge, 1998.

Soetomo. "Persoalan Pengembangan Institusi Masyarakat." Jurnal Ilmu Sosial dan Politik. 10, no. 1 (2006): 51-69.

Uphoff, Norman. Local Institutional Development: An Analytical Sourcebook. Connecticut: Kumarian Press, 1986.

White, Kevin. Pengantar Sosiologi Kesehatan Dan Penyakit. 3rd ed. Jakarta: Rajawali Press, 2011.

Widjaja, Fransiskus Irwan. "Peran Gereja Terhadap Kehidupan Politik Di Wilayah Kepulauan Riau." Real Didache 1, no. 2 (2016): 117-140. 